\title{
Performance of ferritic steel 16MnDR using improved local fracture criterion
}

\author{
Jianhua Pan ${ }^{1,2,}$, Yan Wang $^{2}$, and Mingjie Guo ${ }^{1}$ \\ ${ }^{1}$ State Key Laboratory of Nuclear Power Safety Monitoring Technology and Equipment, Shenzhen, \\ Guangdong 518172, China \\ ${ }^{2}$ Anhui Province Key Lab of Aerospace Structural Parts Forming Technology and Equipment, \\ Institute of Industry \& Equipment Technology, Hefei University of Technology, Hefei 230009, China
}

\begin{abstract}
Based on the finite element analysis and fracture toughness test data, this paper verifies the improved Ritchie-Knott-Rice (RKR) local failure criterion using $16 \mathrm{MnDR}$ ferritic steel for cryogenic pressure vessels. This criterion's applicability to $16 \mathrm{MnDR}$ was verified to verify fracture toughness's different influence factors in the ductile-to-brittle transition temperature (DBTT) region, such as specimen thickness (TST) and temperature. The results indicate that the $\left(4 \delta_{t}, \sigma_{22 c}\right)$ criterion applies to $16 \mathrm{MnDR}$ steel and effectively transfers the minimum $J \mathrm{c}$ value between samples of different temperatures and thickness.
\end{abstract}

\section{Introduction}

Ferritic steel such as the $16 \mathrm{MnDR}$ is a widely used alloy in industrial production for making cryogenic pressure vessels. Because the $16 \mathrm{MnDR}$ ferritic steel has low strength and good plastic properties, it cannot be analyzed based on the traditional linear elastic fracture theory. A transition of the fracture mode from ductile to brittle fracture of the steel is documented at a specific operational temperature. Consequently, the measurement of fracture toughness of the steel has a high degree of uncertainty for the designers and the manufacturers of the cryogenic pressure vessels[1].

Dodds et al.[2] indicate that the thickness variation will result in a minimum value of fracture toughness parameters obtained by test[3][4]. In order to qualitatively study this minimum, Meshii T. et al. proved the existence of this minimum using the $\left(4 \delta_{t}, \sigma_{22 c}\right)$ local fracture criterion and gave a specific method to determine this minimum[5]. Besides, from their research, this criterion provides us with a new idea, that is, the minimum $J$-integral value satisfying $\sigma_{22 d}=\sigma_{22 c}$ in the $\left(4 \delta_{t}, \sigma_{22 c}\right)$ criterion (shown in Figure 1) corresponds to the observed minimum $J_{C}$ value of materials, so we can use this criterion to predict the minimum failure conditions of materials under different conditions.

The $\left(4 \delta_{t}, \sigma_{22 c}\right)$ criterion was used in the present study to predict the minimum failure conditions of $16 \mathrm{MnDR}$ steel. The applicability of the criterion has been verified by fracture toughness data alongside the finite element method under different conditions, i.e., temperature and thickness of the sample.

\footnotetext{
* Corresponding author: jhpan@hfut.edu.cn
} 


\section{Fracture toughness testing}

Firstly, we carried out a low-temperature tensile test according to GB/T 2975-1998 standard[6]. Two strength values of $16 \mathrm{MnDR}$ steel at different temperatures are obtained, as shown in Table 1 . The young's modulus $E$ equal to $201 \mathrm{GPa}$, and Poisson's ratio $v$ equal to 0.3 .

Table 1. Yield and ultimate strength of $16 \mathrm{MnDR}$ steel.

\begin{tabular}{ccc}
\hline Temperature $\left({ }^{\circ} \mathrm{C}\right)$ & Yield strength $\sigma_{\text {ys }}(\mathrm{MPa})$ & Ultimate strength $\sigma_{\text {us }}(\mathrm{MPa})$ \\
\hline-80 & 433 & 631 \\
-70 & 433 & 620 \\
-60 & 419 & 605 \\
\hline
\end{tabular}

According to the GB/T 21143-2007 standard, fracture tests were carried out on the relevant specimens[7]. The specimen type used in the test is the SE (B) specimen, the thickness is set to $15 \mathrm{~mm}$, and the ratio of the initial crack length to the specimen width was kept within a small range $a_{0} / W=0.5$. The dimensional relationship of the specimen used for the test is shown in Figure 2[8][9]. Finally, the experimental data at different temperatures and the data at different thicknesses calculated by the formula (1) are listed in Table 2 to table 4 below.

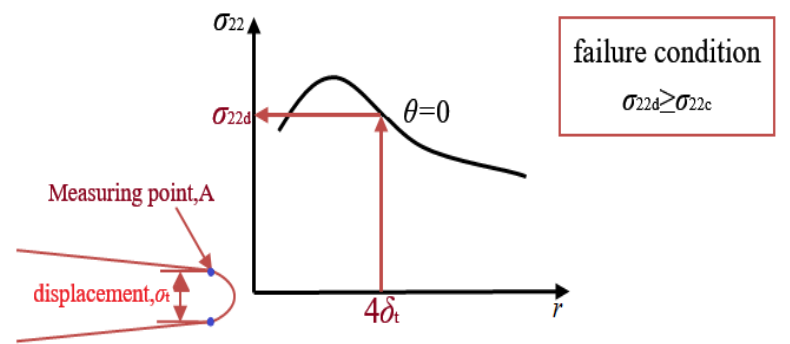

Fig. 1. $\left(4 \delta_{\mathrm{t}}, \sigma_{22 \mathrm{c}}\right)$ failure criterion [7].

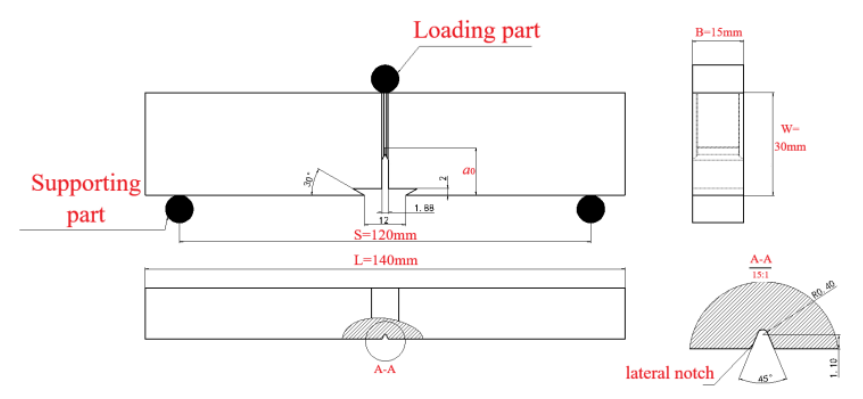

Fig. 2. 0. 59T SE (B) specimen geometry.

$$
K_{J C(I T)}=K_{\text {min }}+\left(K_{J C(x T)}-K_{\text {min }}\right)\left(\frac{B_{x T}}{B_{I T}}\right)^{1 / 4}
$$

$K_{\min }$ equal to $20 \mathrm{MPa} \sqrt{\mathrm{m}}$ for ferritic steels; $B_{I T}$ equals $25.4 \mathrm{~mm}$ for the $1 \mathrm{~T}$ specimen thickness; $B_{x T}$ is the thickness of the specimen we used; $K_{J C(x T)}$ is the values of $K_{J C}$ when the thickness of the sample is $x T$. 
Table 2. Fracture toughness values of the test specimen at $-80^{\circ} \mathrm{C}$.

\begin{tabular}{cccccccc}
\hline Specimen ID & M28 & M29 & M30 & M32 & M33 & M35 & M36 \\
\hline$J(0.59 \mathrm{~T})\left(\mathrm{kJ} / \mathrm{m}^{2}\right)$ & 79.1 & 48.4 & 137.1 & 36.4 & 73.7 & 52.3 & 97.5 \\
\hline$J_{C}(1 \mathrm{~T})\left(\mathrm{kJ} / \mathrm{m}^{2}\right)$ & 63.4 & 108.8 & 29.7 & 39.5 & 59.2 & 42.3 & 77.8 \\
\hline$J_{C}(0.8 \mathrm{~T})\left(\mathrm{kJ} / \mathrm{m}^{2}\right)$ & 71.5 & 44.3 & 123.4 & 33.2 & 66.7 & 47.5 & 88.0 \\
\hline
\end{tabular}

Table 3. Fracture toughness values of the test specimen at $-60^{\circ} \mathrm{C}$.

\begin{tabular}{ccccccc}
\hline Specimen ID & M37 & M38 & M39 & M40 & M41 & M42 \\
\hline$J_{C}(0.59 \mathrm{~T})\left(\mathrm{kJ} / \mathrm{m}^{2}\right)$ & 157.0 & 70.4 & 116.9 & 284.8 & 220.8 & 319.8 \\
\hline
\end{tabular}

Table 4. Fracture toughness values of the test specimen at $-70^{\circ} \mathrm{C}$.

\begin{tabular}{llllllll}
\hline Specimen ID & M8 & M9 & M10 & M11 & M12 & M13 & M14 \\
\hline$J_{C}(0.59 \mathrm{~T})\left(\mathrm{kJ} / \mathrm{m}^{2}\right)$ & 240.4 & 60.8 & 160.1 & 187.1 & 302.4 & 344.0 & 102.3 \\
\hline
\end{tabular}

\section{Finite element analysis}

The SE (B) specimens with thicknesses of 0.59T, 0.8T, and 1T participated in the finite element analysis, and the size of the model was the same as that of the actual specimen in Figure 3. Also, because the specimen exhibits symmetry, the model of $1 / 4$ specimen was chosen to set up. At the crack tip, a cavity with a passivation radius $\rho$ of $3 \mu \mathrm{m}$ was used to simulate the crack tip that existed in the actual test[5]. The material stress and strain data for finite element analysis are shown in Figure 4 below.

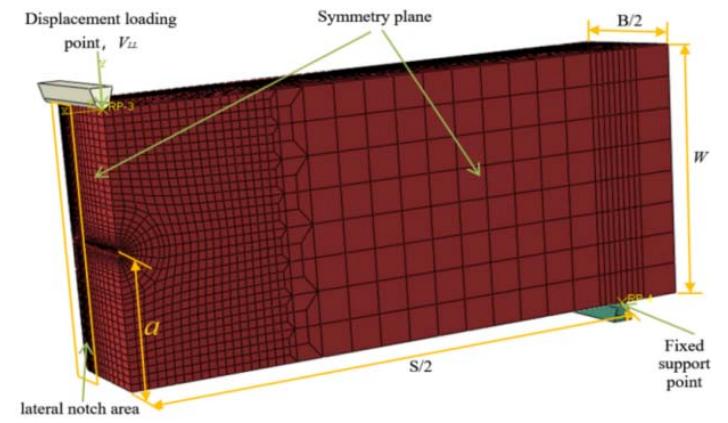

Fig. 3. Finite element model.

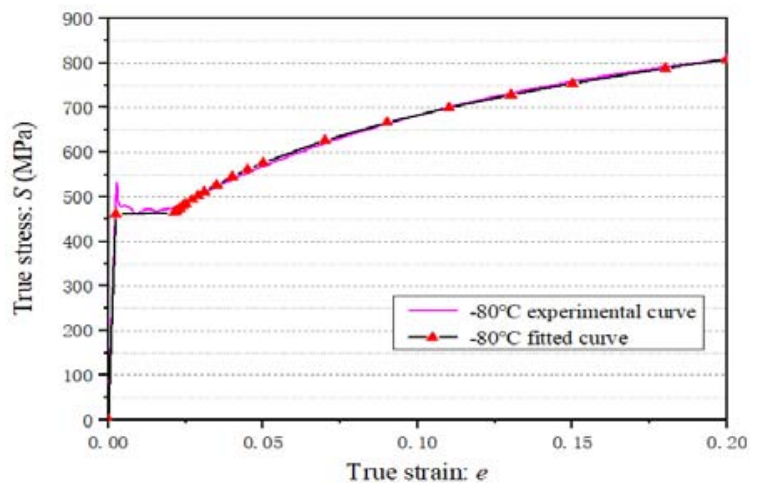

Fig. 4. True stress-true strain curve of $16 \mathrm{MnDR}$ steel at $-80^{\circ} \mathrm{C}$. 
Table 5 shows the results of crack tip opening stress $\sigma_{22 d}$ obtained by finite element analysis under different conditions.

Table 5. Crack tip opening stress $\sigma_{22 d}$ corresponding to experimental fracture toughness(MPa).

\begin{tabular}{ccccc}
\hline$\sigma_{22 d}, 0.59 \mathrm{~T},-60^{\circ} \mathrm{C}$ & $\sigma_{22 d}, 0.59 \mathrm{~T},-70^{\circ} \mathrm{C}$ & $\sigma_{22 d}, 0.59 \mathrm{~T},-80^{\circ} \mathrm{C}$ & $\sigma_{22 d}, 1 \mathrm{~T},-80^{\circ} \mathrm{C}$ & $\sigma_{22 d}, 0.8 \mathrm{~T},-80^{\circ} \mathrm{C}$ \\
\hline 1577.9 & 1604.1 & 1558.1 & 1555.0 & 1627.2 \\
1535.9 & 1561.0 & 1608.2 & 1565.9 & 1616.6 \\
1545.6 & 1600.3 & 1527.6 & 1528.6 & 1635.9 \\
1607.0 & 1610.9 & 1522.9 & 1522.1 & 1597.8 \\
1602.7 & 1615.7 & 1554.2 & 1550.5 & 1626.2 \\
1611.2 & 1620.7 & 1524.8 & 1522.3 & 1619.8 \\
- & 1581.0 & 1570.8 & 1564.5 & 1635.7 \\
\hline
\end{tabular}

\section{Discussion}

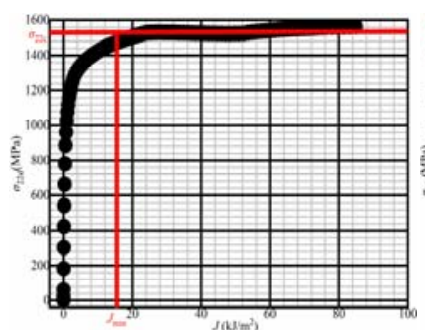

(a) $-80^{\circ} \mathrm{C}$

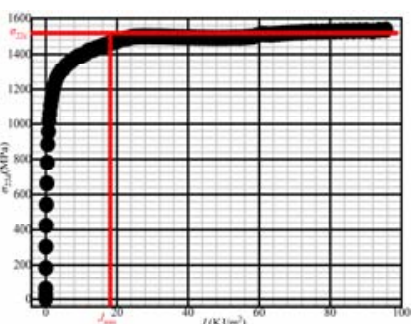

(b) $-70^{\circ} \mathrm{C}$

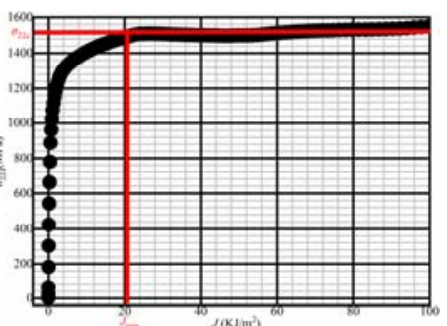

(c) $-60^{\circ} \mathrm{C}$

Fig. 5. The relationship between $\sigma_{22 d}$ and J-integral of $0.59 \mathrm{~T} \mathrm{SE}(\mathrm{B})$ specimens at different temperature.

The relationship between the crack tip opening stress and the J-integral value is plotted to investigate the applicability of the $\left(4 \delta_{t}, \sigma_{22 c}\right)$ criterion for $16 \mathrm{MnDR}$ steel, as shown in Figure 5 . We can see from the figure that with J-integral's rapid change, the crack tip opening stress will converge to a relatively fixed value, and the deviation is minimal (no more than $3.5 \%$ ). This situation fully conforms to the description of the above criterion. Therefore, this fracture criterion can be applied to analyze and evaluate $16 \mathrm{MnDR}$ ferrite steel. When we define the convergence value of the above stress as a fixed limit value $\sigma_{22 c}$, and then define the J-integral value corresponding to this limit value for the first time as the minimum fracture toughness value, we can give a conclusion: the minimum fracture toughness value of $16 \mathrm{MnDR}$ steel at different temperatures can be converted by the $\left(4 \delta_{t}\right.$, $\sigma_{22 c}$ ) criterion. Moreover, by comparing the J-integral value obtained by the fracture toughness test with the figure's data, it can be seen that all the data are more significant than the minimum value defined by us, so this conclusion is reliable.

The results of the other two thickness specimens are shown in Figure 6. The results show that the criterion can also be applied to convert the minimum fracture toughness between specimens when the temperature and thickness are different at the same time. 


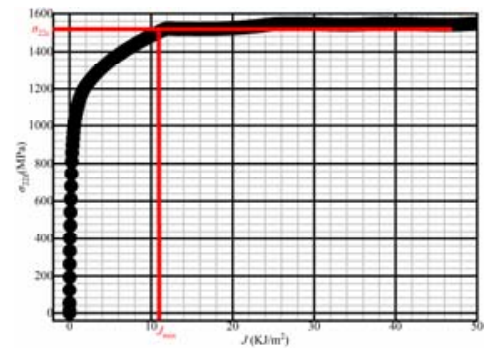

(a) $0.8 \mathrm{~T}$

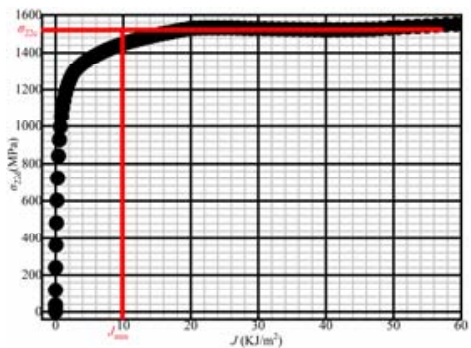

(b) $1 \mathrm{~T}$

Fig. 6. The relationship between $\sigma_{22 d}$ and J-integral of the specimen with different thickness at $-80^{\circ} \mathrm{C}$.

\section{Conclusion}

In this paper, the $\left(4 \delta_{t}, \sigma_{22 c}\right)$ criterion is analyzed with $16 \mathrm{MnDR}$ steel. The results show that the criterion is suitable for the failure analysis of $16 \mathrm{MnDR}$ ferritic steel. Besides, $\left(4 \delta_{t}, \sigma_{22 c}\right)$ criterion can convert the minimum fracture toughness of specimens at different temperatures and convert the minimum fracture toughness of specimens in the presence of temperature and thickness.

\section{References}

1. T. Meshii, T. Yamaguchi, Engineering framework to transfer the lower bound fracture toughness between different temperatures in the DBTT region, Procedia Structural Integrity, 2 (2016) 697-703.

2. R. H. Dodds, T. L. Anderson, M. T. Kirk, A framework to correlate $a / \mathrm{W}$ ratio effects on elastic-plastic fracture toughness $\left(J_{\mathrm{c}}\right)$, Int. J. Fract, 48 (1991) 1-22.

3. H. J. Rathbun, G. R. Odette, M. Y. He, T. Yamamoto, Influence of statistical and constraint loss size effects on cleavage fracture toughness in the transition - a model based analysis, Eng. Fract. Mech. 73 (2006) 2723-2747.

4. H. J. Rathbun, G. R. Odette, T. Yamamoto, G. E. Lucas, Influence of statistical and constraint loss size effects on cleavage fracture toughness in the transition - a single variable experiment and database, Eng. Fract. Mech. 73 (2006) 134-158.

5. T. Meshii, K. Lu, R. Takamura, A failure criterion to explain the test specimen thickness effect on fracture toughness in the transition temperature region, Eng. Fract. Mech. 104 (2013) 184-197.

6. GB/T 2975-1998, Steel and Steel Products-Location and Preparation of Test Pieces for Mechanical Testing. The Standardization Administration of China, 1998.

7. GB/T 21143-2007, Uniform test method for quasi-static fracture toughness of metallic materials, The Standardization Administration of China, 2007.

8. Z. Chen, J. H. Pan, A novel method to estimate the fracture toughness of pressure vessel ferritic steels in the ductile to brittle transition region using finite element analysis and Master Curve method . Int. J. Press. Vessels Pip. 176 (2019) 103949.

9. Z. Chen, J. H. Pan, Estimation of fracture toughness of $16 \mathrm{MnDR}$ steel using Master Curve method and Charpy V-notch impact energy. Theor. Appl. Fract. Mech. 96 (2018) 443-451. 